\title{
UTILIZAÇÃO DE CLORETO DE POTÁSSIO COMO AGENTE EXTRATIVO DE PROTEÍNAS DO QUIABO
}

\author{
L. M. BLANCO ${ }^{1}$, G. H. G. $\operatorname{COSTA}^{1}$ e L. D. PÁDUA ${ }^{1}$ \\ Universidade do Sagrado Coração, Rua Irmã Arminda, 10-50, Jardim Brasil, Bauru-SP \\ E-mail para contato: lemblanco27@gmail.com
}

\begin{abstract}
RESUMO - O quiabo além de ser uma planta amplamente cultivada entre os trópicos e de grande valor nutricional, também possui várias empregabilidades fora da culinária. Uma de suas funções está ligada à grande quantidade de proteínas presentes em sua composição que, por apresentarem ação coagulante, podem ser utilizadas no tratamento de água e do caldo de cana. Entretanto, ainda há poucas informações na literatura que apresentam métodos otimizados de extração destas biomoléculas. Desta maneira, o objetivo do trabalho foi avaliar a utilização de cloreto de potássio como agente extrativo de proteínas do quiabo. $\mathrm{O}$ experimento foi realizado no Laboratório de Biomassa e Bioenergia da Universidade do Sagrado Coração. O delineamento experimental foi inteiramente casualizado, com seis tratamentos e seis repetições. Os tratamentos foram constituídos por água destilada, e soluções de $0,1,0,5,1,0,1,5$ e 2,0mol/L de cloreto de potássio, utilizando-se a proporção de $1 \mathrm{~g} / \mathrm{L}$ de quiabo previamente seco a $65^{\circ} \mathrm{C} / 24 \mathrm{~h}$. Avaliou-se o teor de proteínas dos extratos. Observou-se teores de proteínas entre 5000 e $6700 \mathrm{mg} / \mathrm{L}$, sendo que a utilização de cloreto de potássio $1 \mathrm{~mol} / \mathrm{L}$ aumentou o índice de extração em $12 \%$. Conclui-se que a solução de cloreto de potássio $1 \mathrm{~mol} / \mathrm{L}$ é mais eficaz para extrair proteínas do quiabo.
\end{abstract}

\section{INTRODUÇÃO}

O quiabo é uma planta da família Malvaceae cultivada nos trópicos e sub-trópicos. Adaptada ao clima quente e solos areno-argilosos com grandes quantidades de matéria orgânica presente. Seu fruto é uma cápsula alongada preenchida de sementes. Sua reprodução é através da germinação de sua semente, e seu cultivo é como hortaliça. Após sua germinação a colheita dos primeiros frutos é dada após 60 dias. Os frutos maduros possuem em torno de 50 a 90 sementes, contendo óleo possibilitando seu uso após o refino (LIMA, 2007).

De acordo com Camciuc, Vilarem e Gasec (1997) sua utilização industrial se dá pelas propriedades coloidais presentes no pó das sementes, que possibilita a retenção de impurezas, na substituição do sulfato de alumínio na purificação de águas.

Lima (2007) utilizando o quiabo como auxiliar de floculação em tratamentos de água obteve dados satisfatórios como: o baixo custo do polímero natural, melhora a qualidade do tratamento de água, e ocorre pouca perda das propriedades do polímero após estocagem. Em números isso é observado na remoção de turbidez, representando um percentual superior em 
$4 \%$ com o conjunto coagulante e polímero natural do quiabo (remoção de $92 \%$ ) comparado com a dosagem apenas do coagulante (remoção de 88\%).

As pesquisas realizadas com base nas propriedades do quiabo não indicam a metodologia utilizada na extração destas proteínas.

Desta maneira, o objetivo do trabalho foi avaliar a utilização de cloreto de potássio como agente extrativo de proteínas do quiabo.

\section{MATERIAL E MÉTODOS}

O experimento foi realizado no Laboratório de Biomassa e Bioenergia da Universidade do Sagrado Coração, Bauru-SP, no segundo semestre de 2016. O quiabo foi obtido de centros comerciais da cidade de Bauru.

$\mathrm{O}$ quiabo foi seco em estufa de circulação de ar forçado a $65^{\circ} \mathrm{C}$ por 24 horas. A seguir foi triturado e macerado em cadinho de porcelana, sendo imerso em diferentes soluções, na proporção de $1 \mathrm{~g} / \mathrm{L}$, as quais permaneceram em agitação por 30 minutos. Após o tempo em agitação, o extrato foi filtrado em papel de filtro qualitativo para remoção das partículas insolúveis. As soluções utilizadas foram água destilada e $\mathrm{KCl}$ nas concentrações de $0,1,0,5$, $1,0,1,5$ e 2,0mol/L, além de água deionizada.

Os extratos foram caracterizados quanto ao teor de Proteínas Totais (HARTREE, 1972).

O delineamento experimental foi inteiramente casualizado, com 6 tratamentos e seis repetições. Os resultados foram submetidos a análise de variância pelo teste $\mathrm{F}$, e as médias comparadas segundo teste de Tukey (5\%).

\section{RESULTADOS E DISCUSSÃO}

Na figura 1 estão apresentados os valores médios obtidos pela proteína extraída do quiabo a partir de diferentes molaridades de solução de $\mathrm{KCl}$.

Pode-se observar que houve pouca variação entre as proporções estudadas, mas ainda sim a proporção de $1 \mathrm{~mol} / \mathrm{L}$ obteve seu melhor desempenho atingindo $6723,61 \mathrm{mg} / \mathrm{L}$ seguido da proporção de $1,5 \mathrm{~mol} / \mathrm{L}(6642,40 \mathrm{mg} / \mathrm{L})$. Na literatura a melhor proporção para Cloreto de Potássio tratou-se também de $1 \mathrm{~mol} / \mathrm{L}$. Madrona (2010) e Costa et al. (2016), extraindo a proteína 2S-Albumina das sementes de Moringa oleífera Lamarck utilizando soluções de $\mathrm{KCl}$ em diferentes molaridades, obtiveram valores de $4818,64 \mathrm{mg} / \mathrm{L}$ e $1258 \mathrm{mg} / \mathrm{L}$ respectivamente, quando utilizaram solução de $\mathrm{KCl}$ 1mol/L. 
O desvio padrão, também chamado de barras de erro, apresentado na Figura 1, é quantificado através da análise de variância pelo teste $\mathrm{F}$ e comparado ao teste de Tukey $(5 \%)$. Podemos salientar que todas as seis proporções obtiveram padrão estatístico "A" obedecendo a variação 12,50\% do coeficiente de variação. Observando a Figura 1 certificamos também que o comprimento da barra de erro atende ao valor do coeficiente de variação, ou seja, o valor médio apresenta baixa porcentagem de incerteza na amostra.

Figura 1 - Valores médios obtidos para proteínas extraídas do quiabo por solução de Cloreto de Potássio, nas proporções de $0,1,0,5,1,0,1,5$ e $2,0 \mathrm{~g} / \mathrm{L}$.

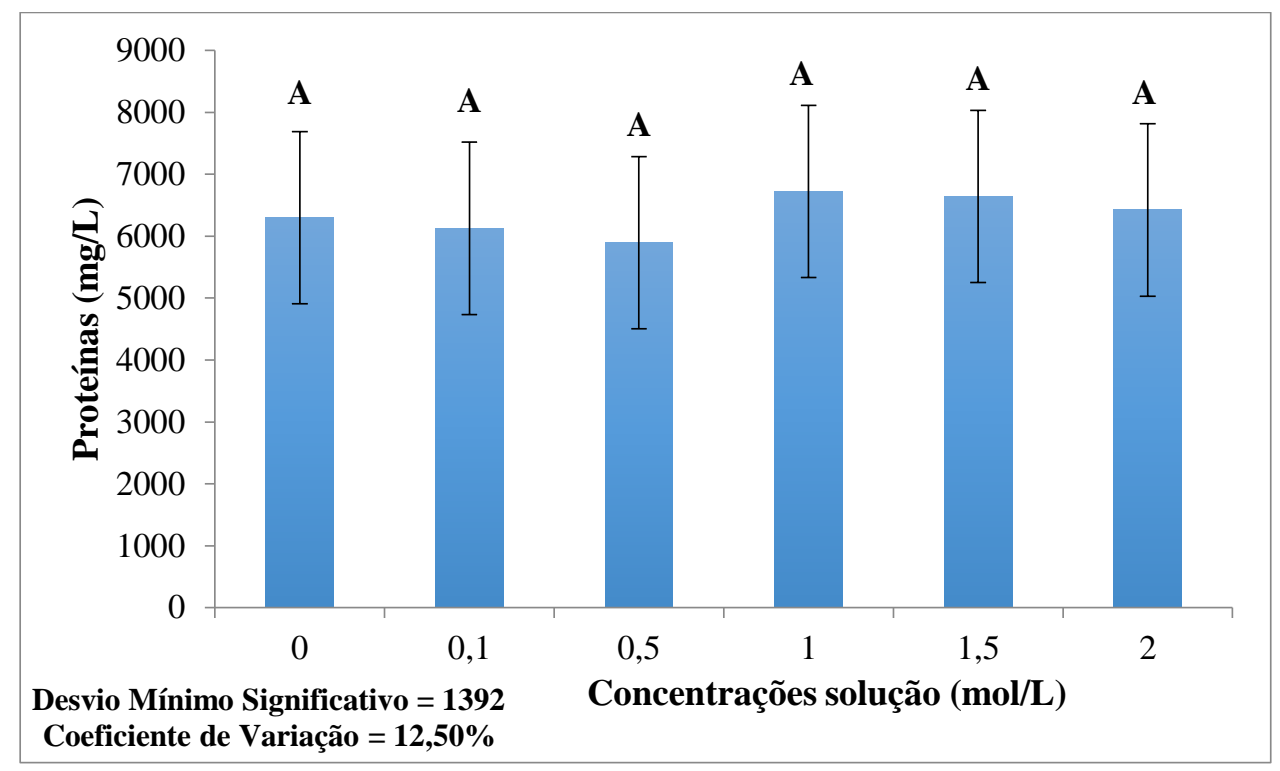

Deve-se destacar que a utilização de soluções salinas facilitam a extração de proteínas presentes em plantas, devido as interações catiônicas e aniônicas que essas promovem com tais biomoléculas. Entretanto, neste ensaio, observou-se que a utilização de somente água destilada foi suficiente para se conseguir índices de extração similares aos obtidos por soluções de $\mathrm{KCl}$ em diferentes molaridades. Neste sentido, este aspecto é interessante do ponto de vista industrial, pois há menor gastos com insumos, possibilitando eficiências similares e maior lucratividade para a empresa.

\section{CONCLUSÃO}

$\mathrm{O}$ presente trabalho conclui que, a melhor dosagem de $\mathrm{KCl}$ para extração de proteínas do quiabo é a de 1,0mol/L $(6723,61 \mathrm{mg} / \mathrm{L})$, mas quando comparado com água destilada $(6126 \mathrm{mg} / \mathrm{L})$ a relação custo benefício faz com que a pequena diferença (aproximadamente $595 \mathrm{mg} / \mathrm{L}$ ) que a concentração de $1 \mathrm{~mol} / \mathrm{L}$ apresenta a mais que a concentração zero tornem a utilização de solução salina a base de Cloreto de Potássio 1mol/L dispensável.

Neste contexto considerando-se a utilização em larga escala, recomenda-se o uso de água destilada como agente extrativo de proteínas do quiabo, visando menores custos ao 
projeto e mesma eficiência.

\section{REFERÊNCIAS}

CAMCIUC, M.; VILAREM, G.; GASET, A. Le gombo, Abelmoschus esculentus (L) Moench, une source possible de phospholipides, Oléaginaux, Corps Gras Lipides v. 4. n 5, 1997.

COSTA, G.H.G.; FREITA, C. M.; MENDES, F. Q.; MUTTON, M. J. R. Extrato de sementes de moringa como floculante de caldo de cana-de açúcar. Pesquisa agropecuária brasileira, Brasília, v.51, n.10, p.1794-1798, out. 2016

HARTREE, E. F. Determination of protein: A modification of the Lowrey method that gives a linear photometric response. Analytical Biochemistry, v.48, n.2, 1972

LIMA, G. J. A.; Uso de polímero natural do Quiabo como auxiliar de floculação e filtração em tratamento de água e esgoto. 2007, 154f. Dissertação (Mestrado em Engenharia Ambiental). Faculdade de Engenharia da Universidade do estado do Rio de Janeiro, Rio de Janeiro.

MADRONA, G. S. Extração/ Purificação do composto ativo da semente da Moringa Oleifera Lam e sua utilização no tratamento de água para consumo humano. Def. em 03/12/2010 176f. Tese de Doutorado - Universidade Estadual de Maringá, Centro de Tecnologia departamento de Eng. Química. Maringá, PR. 